\title{
REVISITACIONES DE TERESA DE JESÚS DESDE EL OTRO LADO: LA DOCTORA MÍSTICA Y EL ESPIRITISMO FINISECULAR*
}

\author{
REVISITS OF TERESA OF ÁVILA FROM THE OTHER SIDE: THE MYSTIC \\ DOCTOR AND THE TURN OF THE CENTURY SPIRITUALISM
}

\author{
Amelina Correa Ramón \\ Universidad de Granada. Granada, España \\ amelina@ugr.es
}

\begin{abstract}
Resumen: En 1904-1905 la escritora espiritista Amalia Domingo Soler publica la sorprendente obra iTe perdono! Memorias de un espíritu, encuadrada en un género de difícil clasificación que se podría denominar biografía de ultratumba, puesto que da forma literaria a las revelaciones recibidas supuestamente a través de un médium en sesiones espiritistas. En este caso parecerían proceder nada menos que de Teresa de Jesús, ofreciéndose una transgresora versión de su reforma, experiencias místicas y reacciones de sus contemporáneos, planteándose que su mensaje habría sido manipulado con el fin de desactivar su carácter subversivo. Tan heterodoxa propuesta alcanzará una exitosa vida editorial y unas notables y llamativas repercusiones, olvidadas hasta la fecha, y de signo ideológico opuesto, por parte de José Blanco Coris y el Padre Eusebio del Niño Jesús.
\end{abstract}

Palabras clave: Teresa de Jesús, espiritismo finisecular, relectura heterodoxa.

\begin{abstract}
From 1904 to 1905, the spiritualist writer Amalia Domingo publishes a surprising work entitled I forgive you! Memories of a spirit, within a genre that is hard to classify and which could belong to the Memories Beyond the Grave one, since they literally shape what are suposed to be revelations given though conducted channeling sessions. In this case, the presumed spiritual entity was Teresa of Ávila, offering a transgressive version of her reformism, mystic experiences and reactions to her contemporaries, as her message had been manipulated in order to deactive its subversive nature. This heterodox proposal would accomplish a highly-successful printing
\end{abstract}

* Este trabajo se inserta dentro del Proyecto I+D "La conformación de la autoridad espiritual femenina en Castilla", FFI2015-63625-C2-2-P, financiado por el Ministerio de Economía y Competitividad del Gobierno de España. 
and a remarkable repercussion that have been forgotten so far, and that is ideologically oposed, by José Blanco Coris and Padre Eusebio del Niño Jesús.

Keywords: Teresa of Ávila, turn of the century spiritualism, heterodox rereading.

Recibido: 12.07.2016. Aceptado: 13.12.2016.

66

... Y tan alta vida espero,/ que muero porque no muero"... Si Teresa de Jesús escribió sus conocidos versos con la mente -y el corazón- puestos en la vida eterna que la esperaría tras su paso por este valle de lágrimas terrenal, lo cierto es que, inesperadamente, alcanzaría de igual modo otro tipo bien distinto de vida post mortem. En efecto, y en el ámbito de los heterodoxos movimientos espiritistas que cristalizarían y alcanzarían gran arraigo al hilo de la crisis espiritual de fin de siglo, y al que, como es bien sabido, se encuentran vinculados autores de primera importancia, como Victor Hugo o Arthur Conan Doyle, entre otros (Gullón, 1990, Arkinstall, 2014 y Correa Ramón, 2002 y 2015), se puede señalar la publicación entre 1904 y 1905 por parte de la escritora sevillana pero afincada en Barcelona, Amalia Domingo Soler (1835-1909) de la extensa obra titulada iTe perdono! Memorias de un espíritu ${ }^{1}$. Su autora fue aclamada como la escritora espiritista más prestigiosa de España, y así el erudito Mario Méndez Bejarano, menos de dos décadas después de su muerte, en su sorprendente Historia de la filosofía en España (hasta el siglo XX) -que incluye y considera asépticamente el espiritismo finisecular como una corriente filosófica más- manifiesta que "Doña Amalia es, sin disputa, la única escritora espiritista de algún mérito" (1928, s. a.: 532). De hecho, la bibliografía contemporánea al respecto reconoce sus indudables valores, como sucedía ya en el estudio pionero de Lily Litvak, "Entre lo fantástico y la ciencia ficción: el cuento espiritista en el XIX" (1994), quien destacaba el valor de sus narraciones desde el otro lado, o en fecha muy reciente, en el completo estudio

${ }^{1}$ Aunque se comentará posteriormente de manera pormenorizada la compleja historia editorial de dicha obra, cabe adelantar que se publicó inicialmente entre 1904 y 1905 en ocho tomos por parte de la barcelonesa casa editorial Carbonell y Esteva, que resultan hoy dificilísimos de localizar. El ejemplar que se ha manejado para la elaboración del presente trabajo procede de la reedición que llevó a cabo algunos años después la conocida Casa Editorial Maucci (Barcelona), en dos tomos, que carece de datos temporales de edición, pero que con toda probabilidad vieron la luz después de 1910, es decir, de manera póstuma. 
monográfico Spanish Female Writers and the Freethinking Press 18791926, de la profesora Christine Arkinstall, quien afirma: "Amalia Domingo Soler, recognized in international bibliographies on spiritism as most significant female figure in the movement, played an extremely active part in freethinking circles and anticlerical thougt from the end of the 1870 ontil her death" (2014: 23).

Dicha obra, que alcanzará una azarosa pero llena de éxitos vida editorial y unas notables y más que llamativas repercusiones, se podría encuadrar en un género de difícil clasificación, que quizás sería dado denominar biografías de ultratumba (Correa Ramón, 2015) puesto que en ellas se da forma literaria a las revelaciones recibidas supuestamente a través de un médium conductor por medio de sucesivas sesiones espiritistas.

En este caso concreto se trataría de las revelaciones transmitidas a lo largo de dos años y nueve meses -en concreto, entre el 18 de febrero de 1897 y el 23 de noviembre de 1899- y comunicadas a través de Eudaldo Pagés, médium parlante del centro espiritista barcelonés de "La Buena Nueva”, al que pertenecía y del que era miembro activo la escritora (Correa Ramón, 2000 y 2002). Este habría recibido el mensaje de un alma del más allá que pretende difundir su vivencia de purificación y superación moral experimentada a lo largo de las diversas existencias que ha encarnado en este mundo (puesto que -no lo olvidemos- el espiritismo explicaba el perfeccionamiento del espíritu humano mediante sucesivas reencarnaciones y la comprensión de las faltas cometidas en vidas pasadas a partir de la expiación en la existencia presente). El mencionado espíritu va relatando en primera persona -según transcribe y anota Amalia Domingo- lo que habrían sido sus diversas vidas ${ }^{2}$, desde una primera datada en una ambigua antigüedad en que conoció la maldad y el vicio, hasta el punto de ocasionar la muerte de uno de sus semejantes, hasta la redención que consiguió con mucho esfuerzo y luchando contra los prejuicios establecidos en la última de sus existencias. Es a ésta a la que se dedica la mayor parte del libro, viniéndose a insinuar mediante toda una serie de notables y más que evidentes coincidencias la posibilidad de que el citado espíritu que revela sus pasados devenires hubiera sido en su última existencia nada menos que Santa

\footnotetext{
${ }^{2}$ En este sentido, la difusión finisecular de determinados conceptos en esa línea, queda de manifiesto en el conocido poema "Metempsícosis", de Rubén Darío, Revista Moderna (México, 1 de septiembre de 1898), luego incluido en El canto errante (1907).
} 
Teresa de Jesús, ofreciendo una transgresora versión de su reforma, sus experiencias místicas y las reacciones de sus contemporáneos, puesto que su mensaje y sus obras habrían sido manipulados por la Iglesia oficial, que la habría acabado canonizando para desactivar así el carácter subversivo de su doctrina (Correa Ramón, 2016: 138-145). Por tanto, esta sorprendente obra de Amalia Domingo Soler plantearía una por completo heterodoxa relectura finisecular de la escritora abulense, generándose, además, a partir de su difusión, una curiosa genealogía de discursos que hasta el día de hoy han permanecido por completo olvidados.

Tal vez habría que comenzar aclarando que iTe perdono! Memorias de un espíritu no plantea abiertamente la identidad de la enigmática comunicante, que aparece designada con el nombre simbólico de Iris, evocando a la par la figura mitológica de la mensajera de los dioses griegos, y la suerte de enlace entre cielo y tierra que representa el fenómeno meteorológico del arco iris (Revilla, 1999: 46). Pero las similitudes que se muestran entre esta misteriosa Iris venida del más allá y la magna figura de Teresa de Jesús son tan evidentes, que en la órbita del pensamiento espiritista se ha dado desde un primer momento por consabida esta identificación, y como tal, se suscitaron lecturas e interpretaciones, algunas de las cuales resultan francamente sorprendentes. De hecho, el presente estudio repasará algunas de las principales consecuencias que la relectura teresiana que atrevida -o valientemente- realiza Amalia Domingo Soler van a acarrear en el curso de los cinco lustros siguientes.

La propia Amalia Domingo, en su "Prólogo", declara: "En las Memorias de un espíritu, hay que saber leer entre líneas" (1910, s. a. I: 5). Y lo cierto es que un lector medianamente avisado enseguida percibiría toda una serie de similitudes de imposible coincidencia casual que conducen a la conclusión de que bajo el nombre de Iris hay que saber leer el de Teresa.

Si recordamos lo aficionada que, según propia confesión, era Teresa de Jesús a la figura bíblica de la Samaritana, puesto que en el capítulo XXX del Libro de su vida manifiesta explícitamente: "iOh, qué de veces me acuerdo del agua viva que dijo el Señor a la Samaritana!, y ansí soy muy aficionada a aquel evangelio" (2011: 364), resulta claramente significativo, que en iTe perdono! Memorias de un espíritu Iris revela que, en una existencia anterior, habría sido precisamente esta mujer de Samaria al que el propio Jesucristo pidió agua para beber (Domingo Soler, 1910, I: 39). 
Por otro lado, y centrándonos ya en la quinta y última encarnación en la que detiene su atención en el libro, los detalles biográficos que se ofrecen se muestran tan parecidos a los de la santa de Ávila que no se puede excluir rotundamente ningún tipo de casualidad.

Así, su padre tuvo dos esposas y el fallecimiento de su madre la dejó huérfana a temprana edad, aunque ésa había sido "una perfecta cristiana" (I: 261) que le enseñó a leer y escribir; pertenecía a una familia numerosa; de pequeña gustaba de leer lecturas caballerescas y religiosas -lo que coincidiría con las novelas de caballería y con las vidas de santos que leía en su infancia Teresa de Jesús, según ella misma revela en el Libro de la Vida-, y de joven ingresó en un convento, si bien contrariando los deseos de su padre, aunque poco después de entrar enfermará gravemente, hasta el punto de que su progenitor se va a ver obligado a llevársela a casa para darle adecuado tratamiento y atenderla en su larga convalecencia. Más adelante emprenderá una labor reformadora y fundará una serie de conventos. Todos estos detalles, como el lector avisado percibe con facilidad, se muestran coincidentes con la biografía de Teresa de Jesús.

Pero además, Iris declara abiertamente: "Por la misión que yo quería desempeñar elegí el suelo español, ahora puedo decir que vine a la tierra española, tierra de hidalgos y de soñadores, tierra de guerreros y de fanáticos, tierra de artistas y de frailes" (I: 261).

En adición a esto, a lo largo de toda la extensísima obra se relatan numerosos episodios de carácter místico, con presencia de visiones sobrenaturales, revelaciones y contactos con la divinidad, además de ponerse de manifiesto una serie de poderes de sanación que Iris emplearía curando a un buen número de necesitados que se cruzan en su camino, cualidades que le vendrían otorgadas directamente por Dios. En el curso de una de las prodigiosas visiones que le sobreviene durante la noche en su celda, Iris recibe la visita de una hermosa figura llena de luz que le dice lo siguiente: “-iCómo te espantas,...!, icómo te aturdes!, icómo te asombras!, icómo te turbas...!" (I, 355).

Resulta evidente que las palabras pronunciadas por el ser de luz vienen a ser, hasta en la métrica, puesto que la frase utiliza una estructura rítmica pentasilábica, un claro reflejo de los muy conocidos versos de Teresa de Jesús: 


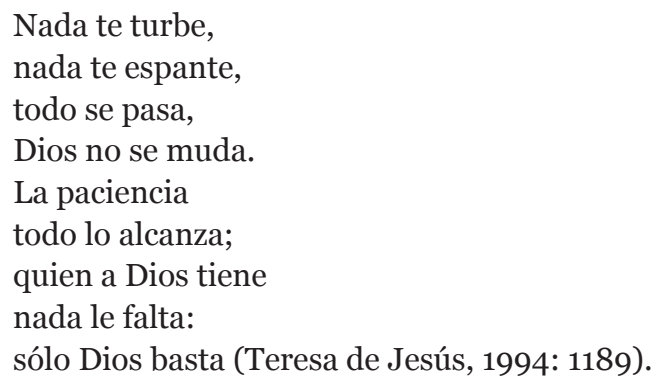

Se podrían mencionar muchos aspectos presentes en iTe perdono! Memorias de un espíritu que remiten sin ambigüedad posible al mundo teresiano, pero por no extenderme demasiado, me ceñiré a dos personajes que aparecen en la obra y que resultan fácilmente reconocibles. En primer lugar, se puede recordar al joven religioso, culto y muy motivado por la renovación que suponen los planteamientos de la emprendedora monja, pero, a la vez, procedente de la alta sociedad y con importantes influencias, que entra en contacto con una ya madura Iris a partir del capítulo LIX, con la que iniciará una relación que se revelará determinante. Los abundantes datos que se ofrecen permiten suponer al lector avisado que se trata de la trasposición de Jerónimo Gracián, cuyos padre y hermanos habían ocupado elevados puestos en la Corte, y al que conoció Teresa de Jesús cuando ésta pasaba ya de los sesenta años y él no tenía más que treinta, profesándole un gran afecto $^{3}$.

Y en segundo lugar, se puede encontrar fácilmente paralelismo con la historia real de Teresa de Jesús en la figura de la rica y poderosa protectora que, según el relato, apoya a Iris en la fundación de sus conventos, pero que, a la postre, se acabará mostrando como una persona interesada únicamente en satisfacer su vanidad, y que intentará por todos los medios controlar a la monja en su propio beneficio. Cabría ver en ella, claro está, la reverberación de lo que sucedió a la escritora abulense con la Princesa de Éboli, y la desafortunada fundación de Pastrana. De hecho, los malos presentimientos asaltarán a Iris desde el comienzo de la relación, y sentirá un

${ }^{3}$ De hecho, la novela de Fernando Delgado Sus ojos en mí (2015), ganadora del XXIII Premio Azorín de Novela, se centra precisamente en el supuesto amor platónico que habría sentido Teresa de Jesús por el joven Jerónimo Gracián, sentimiento que concuerda plenamente con el que se nos narra a lo largo de muy diversos episodios de iTe perdono! 
extraño rechazo que ella misma no sabe explicar hacia quien inicialmente sólo había mostrado su cara amable 4 , hasta que termine por revelarse su verdadera naturaleza.

Estas finiseculares Memorias de un espíritu se presentan en todo momento como una defensa de la tolerancia, la comprensión y, sobre todo, el perdón que se anuncia desde su propio título, y su protagonista se dibuja como una adalid que batalla contra el fanatismo y la intransigencia, vicios todos que se consideran primordialmente encarnados en la Iglesia Católica, que claramente habría malversado el mensaje evangélico de Jesucristo, y que lucha denodadamente por eliminar, o en su defecto manipular, todo mensaje que escape a su control. Y esto es lo que presuntamente habría sucedido con la pionera reformadora del XVI, según se deduce de lo expuesto en la obra de Amalia Domingo. De hecho, numerosos planteamientos de los que Iris proclama con vehemencia disienten, en buena medida, de los que Teresa de Jesús habría sostenido en sus obras, o al menos, en lo que nos ha llegado como versión oficial de las obras teresianas, puesto que lo que insinúa el novedoso planteamiento espiritista sería que, dada la popularidad que había alcanzado en vida, a la Iglesia no le habría quedado más remedio que canonizarla, a fin de integrarla en la oficialidad, pero reescribiendo, eso sí, los escritos salidos de su pluma. Llevando a cabo un rápido repaso de algunos aspectos en que lo proclamado por Iris contraviene a todas luces la ortodoxia establecida, se puede recordar, por ejemplo, la defensa que promueve de una relación directa con Dios, sin necesidad de intermediarios y sin reconocimiento de la autoridad; el rechazo de una visión doliente y cubierta de sangre de Jesucristo, o el elogio de la maternidad de María sin que esto presuponga la conservación de su virginidad. Además de todo esto, se puede destacar de igual modo la posición que defiende con respecto a la clausura religiosa y al celibato ${ }^{5}$, que rechaza de plano al considerar que

\footnotetext{
${ }^{4} \mathrm{Cf}$. "Al verla, involuntariamente sentí en todo mi ser un estremecimiento doloroso, a pesar mío, un sentimiento de repulsión se apoderó de mí" (Domingo Soler, I: 309).

${ }^{5}$ Así, éste sería uno de los casos en que la obra de Teresa de Jesús habría sido presuntamente manipulada, puesto que se pueden recordar algunos pasajes del Libro de la Vida, como el capítulo VII, donde "Trata [...] los daños que hay en no ser muy encerrados los monasterios de monjas", afirmando la autora que "a mí me hizo harto daño no estar en monasterio encerrado " (2011: 158), al mismo tiempo que alerta: "[...] y ansí me parece lo es grandísimo [peligro] monasterio de mujeres con libertad; y que más me parece el paso para caminar al infierno las que quisieren ser ruines que remedio para sus flaquezas" (158).
} 
el ser humano debe aceptar y cumplir con los naturales y sanos instintos con que ha venido a este mundo, que no se considerarían en absoluto fuente de culpabilidad o de pecado. Por tanto, Iris se va a mostrar por completo en contra de la reclusión de las mujeres (y de los hombres) en conventos:

iOh!, sí, sí; de muy buena gana hubiera abierto las puertas conventuales y les hubiera dicho a las mujeres: 'Id y sed madres, que la maternidad es el sacerdocio de la mujer'. Y les diría a los hombres: 'Salid, vestid el honroso traje del trabajador, y creaos familia y trabajad para ella. ¿Para qué tantos mártires? Basta de religiosos improductivos dominados por los deseos de la carne. Yo amo a Dios, sí, le amo; pero no desdeño el amor del hombre. [...] Yo amo, yo deseo, yo ansío amor, amor y vida, amor y reproducción (II: 85).

La evidencia de los riesgos que conlleva la valiente postura que Iris mantiene empujarán a su amigo el sacerdote -en quien, a pesar de la intensa admiración que ella le inspira predomina, no obstante, la voluntad de acatar estrictamente las normas establecidas y un deseo no exento de vanidad de permanecer en la órbita de las jerarquías eclesiásticas- a alertarla de que, cuando a ella le llegue el momento de la muerte, posee indicios suficientes como para suponer que él será el encargado de rehacer sus textos con el objetivo de volverlos aceptables y desactivarlos así de todos sus contenidos problemáticos ${ }^{6}$ :

[...] os diré que estéis preparada, porque día llegará, y no muy lejano, que me harán juez de vuestras obras poéticas: yo seré el censor de vuestros escritos, lo presiento, y mis presentimientos no fallan, y cuando ese día llegue, preparaos para sufrir lo que no habéis sufrido todavía, porque yo seré la deshonra de vuestras obras, volviendo lo negro blanco, y lo blanco negro (II: 894-95)7.

${ }^{6}$ Lo que concuerda, en buena medida, con la realidad histórica de la ya mencionada figura de Jerónimo Gracián, que trabajó durante varios años en pro de la beatificación de Teresa de Jesús y promovió la publicación de sus obras.

${ }^{7}$ El motivo de esta manipulación de sus textos que el sacerdote le anuncia radicaría en que "la Iglesia no quiere vuestras obras, porque su contenido es la muerte de sus ídolos, la excomunión de su comercio ilícito, la humillación de su impía soberbia, la luz disipando la sombra, el amor destruyendo los cálculos del egoísmo" (II: 96). 
No obstante, ya a lo largo de iTe perdono! Memorias de un espíritu, el lector se va encontrando con diversos episodios en que Iris manifiesta su angustia y su frustración al mostrarse consciente de que su mensaje va a ser desvirtuado por completo y sus palabras falseadas ${ }^{8}$. Y en este sentido, resulta especialmente revelador, a la vez que explícito, el brutal parlamento que se le dirige poco antes de su muerte:

Tenéis fama de santa, el pueblo ya os ha santificado; millones de enfermos os han bendecido, centenares de hambrientos os llaman su salvación; con mucho menos se puede proclamar santa a una mujer, pero como vuestros escritos y vuestras acciones no están dentro del molde religioso, los padres de la Iglesia, amigos y conservadores del dogma, no queremos vuestra historia con sus sueños y sus delirios [...]; no queremos, no, vuestra verídica historia, por eso hemos quemado vuestras obras, y quemaremos cuantos papeles toquéis y en ellos dejéis vuestros pensamientos; pero consecuentes con nuestro credo, y fieles servidores de la Iglesia, hemos escrito una historia, que pasará por auténtica, digna de vos; os haremos santa, teóloga, doctora, todo lo que se puede ser de grande de nuestra Iglesia (II: 347).

A Iris, por tanto, enfrentada a la fuerza inmensa y todopoderosa de una institución dispuesta a todo con tal de conservar su bien establecido estatus y que a lo largo de su ya extensa historia se ha caracterizado siempre por eliminar incluso mediante la violencia cualquier elemento disidente, no le quedará más opción que confiar en una justicia más allá de la muerte. En encomendar la difusión de su íntima verdad y de su auténtico mensaje a un futuro lejano. De hecho, en la obra de Amalia Domingo Soler se encuentra un episodio en el que leemos:

Escribí tanto y tan a gusto, que hasta la media noche no dejé mi trabajo, y entonces, oí una vocecita que me dijo: "Bien has hecho en escribir, porque ya no te robarán tus escritos; después de muerta, entonces... sí, te los cambiarán, según convenga a la Iglesia; pero luego, más tarde, tú escribirás de nuevo, y entonces resplandecerá la verdad, porque ésta no

${ }^{8} \mathrm{Cf}$. las siguientes palabras: “iMi historia!, un tejido de fábulas ridículas!, imi santidad!, imi santidad fundada sobre irrisorias mentiras! [...] iquieren deshonrarme en vida y santificarme en muerte...!” (II: 347-348). 
puede permanecer envuelta en las brumas de las mentiras religiosas” (I: 413).

Y esto es lo que vendría a ser, precisamente, el libro publicado por Amalia Domingo Soler, es decir, la segunda oportunidad que, al hilo del auge experimentado por el espiritismo finisecular, concebido en todo momento como una vía científica de acceso al otro mundo (Correa Ramón, 2015), y cuyas bondades predican con entusiasmo sus páginas, se le habría presentado a la mística, reformadora y valiente Iris para exponer ante el mundo su verdad, para dejar de manifiesto la absoluta tergiversación que su vida y su obra habrían sufrido.

Como ya se adelantó, la arriesgada propuesta que lanza Amalia Domingo Soler por boca del locuaz espíritu manifestado a lo largo de tantas sesiones mediúnmicas, alcanzará un arrollador éxito comercial. De hecho, la autora sevillana afirma en un "Prólogo" fechado el 5 de enero de 1904 que muchos seguidores han solicitado a la casa editorial Carbonell y Esteva la publicación de estas supuestas revelaciones del espíritu denominado Iris. Al parecer, en efecto dicha editorial barcelonesa publicó la obra en ocho tomos entre los años 1904 y 1905, tomos que resultan hoy en día bastante difíciles de localizar' y que tuvieron tanto éxito que, al menos el primero, alcanzó una reedición muy poco después de salir. No obstante, pocos años después la Casa Editorial Maucci llevó a cabo una segunda, en dos tomos más voluminosos, que omiten (tal y como solía ser habitual en la época) que se trataba de una reedición, así como carecen de datos temporales de edición, aunque todo indica que data de comienzos de la década de los años diez ${ }^{10}$.

Pero el éxito de la obra de Amalia Domingo estaba destinado a ir más allá de una mera cuestión editorial. Y lo cierto es que su publicación iba a provocar, en efecto, en los siguientes lustros, como ya se anticipó, una llamativa y prolongada secuela, que comenzaría -siguiendo la misma línea heterodoxa y anticlerical de la autora sevillana- cuando José Blanco Co-

\footnotetext{
${ }^{9}$ Yo misma tan sólo he logrado hacerme con los números 1,3 , 7 y 8, tras diversas pesquisas en librerías de viejo y catálogos de internet.

${ }^{10}$ Lo cierto es que en la cubierta consta el dato de los diversos premios y medallas recibidos por la editorial en diversas Exposiciones, siendo la última citada la de Buenos Aires de 1910, por lo que la edición tiene que ser de ese año o posterior.
} 
ris (1862-1946), un notable pintor malagueño formado en Roma (E.G.M., 2002: 116), cuya obra artística continúa figurando a día de hoy en catálogos y subastas de arte, tiene conocimiento de la historia narrada por la escritora sevillana, quedando tan vivamente impresionado por ella que la incorpora y reactualiza dando un paso más allá en una obra propia, que lleva por título nada más y nada menos que Santa Teresa, médium. Es decir, la hasta ahora pudorosa -o cauta- Iris quedaría desvelada por completo y las vivencias sobrenaturales que se relatan o analizan son ya directamente adjudicadas a la doctora mística, sin nombres interpuestos.

Además de destacar en ámbitos artísticos, tanto con obras de creación, como con diversas publicaciones teóricas, y de llegar a ser a partir de 1902 profesor numerario de dibujo artístico en la Escuela de Artes y Oficios de Madrid, tras haber ejercido inicialmente la docencia en la Escuela de Bellas Artes de Málaga (E.G.M., 2002: 116), así como secretario del Círculo de Bellas Artes, José Blanco Coris fue igualmente escritor, y como tal lo recoge Francisco Cuenca, en el segundo tomo de su casi legendaria obra Biblioteca de autores andaluces contemporáneos, editada en La Habana en 1925. Según palabras de Cuenca, en Blanco Coris hay "una espiritualidad panteísta que sólo saben sentir y expresar los que tienen el don del Arte" (II: 51). De igual modo, recoge cómo este "excelente artista" demostró interés hacia el pujante espiritismo de la época, en el marco del cual escribió cuatro obras ${ }^{11}$ : Flor de luz (colección de dictados medianímicos), Por qué soy espiritista: estudio crítico doctrinal sobre la sugestión y el espiritismo ${ }^{12}$, Cómo se habla con los muertos, y, claro está, Santa Teresa, médium (II, 52). De ninguna de ellas se ofrece la fecha de edición ${ }^{13}$, y, en el caso que nos interesa,

${ }^{11}$ A las obras mencionadas por Francisco Cuenca, y siempre dentro del ámbito del espiritismo, habría que añadir La Magia del misterio: estudio enciclopédico educador y anecdótico sobre la tierra, el hombre, el alma, la inmortalidad, la providencia, la encarnación, la locura, el sueño, la precocidad, la inspiración, la muerte, y la idea de Dios (Barcelona: Editorial Maucci, 191?) y la novela Sonatas macabras (Madrid, Prensa Gráfica, 1925), que recoge David V. Almazán Tomás (2004: 506) en su estudio sobre el Manual de artes decorativas de Blanco Coris.

${ }^{12}$ No obstante, se encuentra una errata en el título, al consignarlo como Porque soy espiritista, lo que sucede inexplicablemente de igual modo en la lista de "Obras del mismo autor" que se incluye al final del volumen Santa Teresa, médium.

${ }^{13}$ Como tampoco figuran en la entrada dedicada a Blanco Coris, que, firmada por E.G.M, figura en el Diccionario de escritores de Málaga y su provincia (2002: 116-117). 
tampoco consta en el volumen año de publicación, careciendo de colofón final que pudiera arrojar luz al respecto ${ }^{14}$.

En la "Introducción" de su obra, Blanco Coris hace memoria de cómo Teresa de Jesús llegó a su vida, y resulta curioso constatar cómo fue el arte el que propiciaría su primer contacto con ella, ya que -recuerda- en la Exposición Nacional de Bellas Artes de 1884 tuvo ocasión de contemplar en el pabellón de exposiciones del madrileño Parque del Retiro un cuadro de José Alcázar Tejedor "en el que se representaba a Santa Teresa en una de sus visiones celestiales” (s. a.: 9), quedándosele desde ese momento intensamente grabado. Al parecer, la figura de la mística estaba predestinada a convertirse en una suerte de constante en su vida, ya que algún tiempo después, en su Málaga natal, le sería encargado un retrato suyo, para lo cual el pintor acudiría al Convento de Carmelitas Descalzas de la localidad, consiguiendo que le dejasen en préstamo un hábito de la Orden que ordenó vestir a la modelo que le iba a servir de inspiración. Dicho cuadro pasaría a formar parte de alguna colección privada, con toda probabilidad, desconociéndose en la actualidad su paradero. Así el propio Blanco Coris confiesa que la figura de Teresa ha permanecido indeleble:

Su imagen no ha dejado de visitar la memoria durante la tercera parte de mi vida (10).

Con lo que pudiera verse como una especie de predisposición, el pintor relata cómo a sus manos llegó por casualidad iTe perdono! Memorias de un espíritu, y el profundo efecto que le causó. De hecho, afirma que las

devoré con deleite, pues era una colección de dictados medianímicos, publicados por la reputada escritora espiritista Amalia Domingo Soler, referentes a la vida de la Santa carmelita.

Esta obra me impresionó fuertemente, inspirándome la idea profunda de que Santa Teresa de Jesús, cuya vida y milagros se encarga ella misma de ofrecernos en su intimidad y extensión, fue una médium por-

${ }^{14}$ La fecha, indeterminada, sería, por tanto, posterior a la publicación de la obra de Amalia Domingo Soler (1904-1905), pero anterior, sin duda, a 1921, fecha en que, como se verá más adelante, el P. Eusebio del Niño Jesús declara haber encontrado en Cuba un ejemplar de dicho libro. 
tentosa, que a haber tenido una dirección técnica en sus experiencias, hubiera alcanzado la meta de esta facultad humana (10).

A raíz de este proceso de lectura que sacudió al pintor desde lo más hondo, surgió en él la idea de bucear por sí mismo en la producción literaria de la escritora abulense, y en testimonios de autores coetáneos, para plantear la tesis que adelanta abiertamente el título de su libro, y que expone en el párrafo antes mencionado, es decir, que Teresa de Ávila fue una mujer dotada por capacidades de mediumnidad y que las visiones, experiencias extáticas y revelaciones percibidas se habrían debido a las especiales cualidades que harían de ella una "sensitiva", por utilizar la terminología del propio ámbito. Pero Blanco Coris no se va a quedar tan sólo en la revisitación de la obra teresiana con esta intención, sino que también, como relata en su libro, acude a un par de sesiones espiritistas "en casa de una distinguida actriz" (77), en las cuales el propio espíritu de Teresa de Jesús habría hablado por boca de la médium, confirmando al pintor lo atinado de las tesis que plantea en su libro. Así -afirma - "esta insistencia mía en argumentar sobre la mediumnidad de Santa Teresa está confirmada por ella misma ante testigos" (77), cuyos nombres dice no consignar por prudencia y discreción. Este supuesto espíritu que se manifiesta a través de una médium cuyos rasgos físicos parecen recordar precisamente a los de la mística doctora (79), habría alentado al pintor a continuar su obra, si bien advirtiéndole de los riesgos que correría por parte de una Iglesia Católica que ya en vida habría intentado sofocar la radical heterodoxia de la escritora.

Y precisamente en esa línea nos vamos a encontrar con el tercer eslabón de esta peculiar cadena, que viene, de algún modo, a cerrar el círculo y a intentar devolver a Teresa al apacible redil de los indiscutibles fieles sobre los que no se cierne sombra alguna de sospecha, del mismo modo que nos presenta al tercero de los personajes que protagonizan esta peculiar relectura finisecular de la vida y obra de Teresa de Jesús. De este modo, si las dos primeras interpretaciones respondían a una ideología claramente heterodoxa y anticlerical, esta última, muy por el contrario, procede de la más firme ortodoxia católica, y tiene como protagonista precisamente a un sacerdote, el Padre Eusebio del Niño Jesús, quien, nacido en 1888 en un pequeño pueblo leonés, vistió el hábito carmelita descalzo en Segovia en 1903, profesando un año más tarde. De salud frágil y quebradiza, pero es- 
píritu inquieto y actividad incansable, en 1917 fue trasladado a Cuba, donde permaneció por espacio de diez años (Rodríguez, 2007: 29-73), buena parte de los mismos en compañía de su hermano Valentín, también carmelita.

Aficionado a las letras, y autor de varias obras así como colaboraciones periodísticas, el mismo P. Eusebio relata cómo, cuando andaba buscando una serie de obras científicas, la casualidad -el mismo factor que llevó a las manos de Blanco Coris el libro de Amalia Domingo Soler- puso en sus manos, dice: "un catálogo de libros de los más raros e imaginables que darse pueden" (Niño Jesús, 1929, I: 1), y de entre ellos le sorprendió precisamente por lo llamativo del título uno, que adquirió con presteza. Ese libro era, claro está, Santa Teresa, médium, de José Blanco Coris. Como religioso de la orden, el P. Eusebio va a entender como un terrible agravio contra su fundadora el librito -o "libelo", como él lo llama- de Blanco Coris, y empeñándose como en una cuestión personal, acomete la formidable empresa de contrarrestar mediante su pluma la obra del pintor malagueño. De este modo, a las ciento treinta y tres páginas que lo componían le va a oponer nada menos que unas mil doscientas páginas, repartidas en dos voluminosos tomos (de casi 500 y casi 700 páginas respectivamente), de su monumental y sin duda llamativa obra Santa Teresa y el espiritismo.

La motivación que guía al P. Eusebio va a ser en todo momento descalificar a José Blanco Coris, y de paso también, aunque subsidiariamente, a Amalia Domingo Soler, e ir desmontando todos y cada uno de los argumentos que se habían aportado en la línea de relacionar a Teresa de Jesús con las cualidades mediúmnicas o con la posibilidad de sus visitas de ultratumba. Pero lo verdaderamente sorprendente de la obra del carmelita es que se revela como un auténtico conocedor de las doctrinas espiritistas, que conoce los nombres de sus fundadores y apóstoles (Allan Kardec, Camille Flammarion, Madame Blavatsky, Annie Besant, etc.), está al tanto de la historia de este movimiento finisecular y con exactitud domina y reproduce la terminología característica. No en vano dedica casi setecientas páginas a lo que considera los Postulados cardinales del espiritismo, citando una extensa variedad de fuentes y dominando la bibliografía de la doctrina. Quizás en este punto convenga mencionar que, aparte de lo que pudiera haberse documentado -que sin duda lo haría, y mucho, tal y como se deduce de su compleja obra-, el P. Eusebio del Niño Jesús, en el siglo, Ovidio Fernández Arenillas, había tenido ocasión de entrar en contacto directo 
con creyentes espiritistas durante sus años de estancia cubana (Rodríguez, 2007: 42-43). De hecho, su biógrafo, José Vicente Rodríguez, informa de cómo la abundancia del espiritismo que se encontró durante el periodo que estuvo destinado en la ciudad caribeña de Camagüey le hizo ya interesarse por el fenómeno y escribir sobre ello (2007: 42-43), lo que justificaría lo llamativo de su dominio sobre el tema

Estos tres inusuales libros a los que se ha dedicado el presente artículo han quedado durante décadas en el olvido, quizás con la excepción parcial de iTe perdono! Memorias de un espíritu, que sí ha alcanzado estima y reconocimiento incluso a nivel mundial, si bien recluido en el restringido ámbito del espiritismo.

Pero todos ellos merecen ser conocidos y reconocidos, porque toda historia, lejos de ser lineal o responder a unos parámetros establecidos o prefijados, es más bien compleja, poliédrica y heterogénea. Y las obras que sobre la mística abulense nos han legado Amalia Domingo Soler, José Blanco Coris y el P. Eusebio del Niño Jesús nos ofrecen unas facetas de su historia, o de la historia de su recepción, que habiendo permanecido ocultas, se muestran, sin duda alguna, fascinantes e inusitadas para el lector curioso que se asoma a sus enigmáticas páginas en pleno siglo XXI.

\section{Referencias}

Almazán Tomás, D. V. (2004). El pintor José Blanco Coris (1862-1946) y su manual de arte decorativo (1916): la enseñanza del arte extremo oriental y el fenómeno del japonismo en España. Artigrama, 19, 503-521.

Arkinstall, C. (2014). Spanish female writers and the freethinking press 18791926. Toronto: University of Toronto Press.

Blanco Coris, J. (s.a. [a. 1921]). Santa Teresa, médium. Madrid: Reus.

Correa Ramón, A. (2000). Librepensamiento y espiritismo en Amalia Domingo Soler, escritora sevillana del siglo XIX. Archivo Hispalense LXXXIII, 254, 75-102.

. (2002). Amalia Domingo Soler, una escritora en la sombra. En A. Domingo Soler, Cuentos espiritistas (pp. 7-54). Ed. Amelina Correa Ramón. Madrid: Clan.

. (2015). Ce que dit la bouche d'ombre: Amalia Domingo Soler y la revelación hispana de las sombras. En A. Soria Olmedo y M.A. García (eds.), La literatura no ha existido siempre. Para Juan Carlos Rodríguez. Teoría, 
historia, invención (pp. 105-117). Granada: Editorial Universidad de Granada.

. (2016). Nada te turbe, nada te espante: tres lecturas disidentes de Teresa de Jesús en el fin de siglo hispano. e-Humanista, 32, 126-148. Disponible en http://www.ehumanista.ucsb.edu/sites/secure.lsit.ucsb.edu.span. d7_eh/files/sitefiles/ehumanista/volume32/9\%20ehum32.st.correa.pdf.

Cuenca, F. (1925). Biblioteca de autores andaluces contemporáneos. Tomo I. La Habana: A. Dorrbecker.

Darío, R. (1953). Metempsícosis. El canto errante. Obras completas. Tomo V: Poesía (pp. 962-963.) Madrid: Afrodisio Aguado.

Delgado, F. (2015). Sus ojos en mí. Barcelona: Planeta.

Domingo Soler, A. (s.a. [h. 1910]). iTe perdono! Memorias de un espíritu (2 tomos). Barcelona: Casa Editorial Maucci.

E. G. M. (2002). José Blanco Coris. En C. Cuevas (dir. y ed.), Diccionario de escritores de Málaga y su provincia (pp. 116-117). Madrid: Editorial Castalia.

Gullón, R. (1990). Direcciones del Modernismo. Madrid: Alianza.

Litvak, L. (1994). Entre lo fantástico y la ciencia ficción: el cuento espiritista en el XIX. Anthropos. Boletín de información y documentación, 154-155, 83-88.

Méndez Bejarano, M. (s. a. [1928]). El espiritismo. Historia de la filosofía en España (hasta el siglo XX) (pp. 515-533). Madrid: Renacimiento.

Niño Jesús, P. E. del. (1929). Santa Teresa y el Espiritismo. Primera parte: Mediumnidad teresiana. Burgos: Tipografía de El Monte Carmelo.

Revilla, F. de. (1999). Diccionario de iconografía y simbología ( $3^{\mathrm{a}}$ ed. ampliada). Madrid: Cátedra.

Rodríguez, J. Ve. (2007). La dichosa ventura. 16 carmelitas descalzos en Toledo. Madrid: Editorial de Espiritualidad.

Teresa de Jesús, Santa. (1994). Obras completas. Ed. E. Llamas, T. Egido, D. de Pablo Maroto, J. V. Rodríguez, F. Antolin, L. Rodríguez Martínez. Madrid: Editorial de Espiritualidad. . (2011). Libro de la vida (16 a ed). Ed. Dámaso Chicharro. Madrid: Cátedra. 